\title{
The Ecological Substance of Environmental Problems and Exploration of Ecological Remediation
}

\author{
Zhaoyun Li \\ Department of State Owned Assets and Laboratory Equipment \\ Linyi University \\ Linyi, China 276000
}

\begin{abstract}
Environmental problems have been cosmopolitan restrictive factor of social economic development and improvement in people's living standard, and ecological remediation is a series of scientific methods of solving environmental problems. The following paper summarizes the specific performance of environmental problems, analyzes the ecological substance of environmental problems, and explores the ecological remediation and its application practice. Finally, the difficulties of ecological remediation are put forward, in order to provide some reference for the technical research and policy research of ecological remediation.
\end{abstract}

Keywords - environmental problems; ecological remediation; ecological substance; ecosystem; difficulties

\section{ENVIRONMENTAL PROBLEMS AND ITS PERFORMANCE}

Environmental problems refer to changes in the quantity and quality of the environment caused by natural or human activities during the global or regional environment, and the impact of such changes on human survival and development. Environmental problems can be broadly divided into two categories: original natural environment problems and secondary environment problems. Original natural environment problems are caused by the natural forces, and also called the first environment problems, such as environment problems caused by volcanic eruptions, earthquakes, floods, droughts, landslides and so on. Ecosystem destruction and environmental pollution caused by human production and life endanger the survival and development of human beings in turn, the above phenomenon had been called secondary environment problems. Now, the environment problems generally refer to secondary environment problems, which can be divided into two categories: one is environmental destruction caused by human unreasonable development and use of natural environment and resources, such as grassland degradation caused by overgrazing, soil erosion and desertification caused by deforestation and so on; one is environment pollution caused by urbanization and the rapid development of industry and agriculture.

According to the scope and depth of the impact of environment problems, they can be divided into regional environment problems and global environment problems. The regional environmental problems are attributed to ecological destruction and environment pollution. The concrete manifestations are ecological destruction such as soil erosion, biodiversity decreasing, land desertification and wetland landscape disappearance, and pollution of atmosphere, water, soil and noise. Global environmental problems are mainly expressed in the greenhouse effect, global climate change, destruction of the ozone layer, acid rain and so on. Different environmental problems are not independent each other, they interact as both cause and effect, intercross and strengthen coordination, making the problems more complicated.

\section{THE ECOLOGICAL SUBSTANCE OF ENVIRONMENTAL PROBLEMS}

The substance of the environmental problems is the ecological problems that harm survival and development of human caused by changes of the different scale ecosystem of the earth.

Ecological destruction is due to human unreasonable development and utilization of the natural environment and resources, resulting in change or disappearance of some biotic communities during regional ecosystem, the destruction of regional ecosystem structure, loss of ecological services for human. Such as grassland degradation caused by overgrazing, soil erosion and desertification caused by deforestation and so on, which cause the disappearance of the West Asian civilization and the Mayan civilization, the destruction of western China's civilization and the southward shift of China's economic center.

Environmental pollution is the result of earth ecosystem's evolution that is adverse to human survival and development, because during the process of human life and production, human consciously or unconsciously reduce or increase the link of earth ecosystem material cycle, causing the accumulation of certain substances, forcing the earth ecosystem to run self-regulation. Environmental pollution including air pollution, water pollution and soil pollution, their pollutants are divided into degradable and nondegradable pollutants. Non-degradable pollutants are heavy metals and poisonous substance such as mercuric salt, phenol, DDT etc. These pollutants can't degrade in the natural environment or can be only slowly decomposed. So in the ecosystem, they continue to accumulate and increase the concentration along the food chain, and finally endanger the human survival and health. Degradable pollutants such as 
domestic waste, part industrial pollution, thermal pollution etc, which pollutants can be quickly decomposed through the biological processes of natural processes and then go to next step of the material cycle. But when the amount of input into the environment over the natural decomposition force or when the decomposition of the material that into the next link over the next material cycle link's threshold, the natural ecosystem will run abnormal self-regulation, resulting in abnormal changes in natural ecosystems, and the result of changes will be adverse to human survival and development.

Global environmental problems are the results of natural ecosystem abnormal self-regulation, and the results are also due to human interference over the regulatory threshold of natural ecosystem. For example, the greenhouse effect and global change are the performance of this problem: With earth going through a long evolution, the concentration of atmospheric $\mathrm{CO}_{2}$ in the process basically make a short-term ends meet, since entering the industrial society, human use fossil fuels abundantly for their own development. The result is not only release heat to nature of to keep the temperature rise, but also release $\mathrm{CO}_{2}, \mathrm{SO}_{2}$ and nitrogen oxides to atmosphere. Part of $\mathrm{CO}_{2}, \mathrm{SO}_{2}$ and nitrogen oxides go back to the ground with precipitation and plant uptake. In this term, a large amount of $\mathrm{CO}_{2}$ accumulates to increase its concentration, causing the natural ecosystem run selfregulation. This means increasing the temperature to increase the earth plant area and growth rate and increase the carbon capacity of plants to achieve the dynamic balance of $\mathrm{CO}_{2}$ in the atmosphere. However, the greenhouse effect of the earth will cause sea level rise and unpredictable storm surge, which directly affect human survival, life and development.

\section{THE ECOLOGICAL REMEDIATION AND ITS APPLICATION PRACTICE}

\section{A. The Theory and Technology of Ecological Remediation}

Ecological remediation is using ecosystem principles, taking various methods to remedy damaged ecosystem structures, rebuilding healthy ecosystems, strengthening ecosystem service function to human, and enabling ecosystem that need to be renovated to achieve virtuous cycle of overall coordination, self-control and self succession. Ecological remediation includes ecological remediation, ecological reconstruction and ecological improvement. The ecological remediation technology is one or more sets of technology and execution combination program that according to the interacted and coordinated developed theory of every ecosystem elements and each subsystem, through the scientific experiments and practice, aimed at the functional requirements and objectives of the human remediation object, organically combined kinds of physical, chemical and biological engineering technology.

The ecological remediation theory focuses on the interrelationship between the earth ecosystem and the regional subsystems and inside the regional subsystems, the interrelationships between the components of different scale ecosystems and their mutual acting mechanism, the ecosystem biological factors' absorption and degradation to pollution material. It pays attention to the healthy evolution of the earth ecosystem, reflects the regional and comprehensive of geography and the concept of harmony between human and nature. The ecological remediation technology emphasizes the overall function of the ecosystem, the coordination and comprehensiveness of various remediation methods. And it emphasizes that ecological management is an important guarantee for the ecological remediation to be carried out smoothly and the ecosystem self-benign evolution.

Ecological remediation not only includes the remediation, reconstruction and improvement of human health ecosystems According to the functional requirements of human ecosystem Control the biological structure of the system and using biological factors to degrade and absorb pollutants are also an important part of ecological remediation.

\section{B. The Application Practice of Ecological Remediation}

Practice of ecological remediation to ecosystem degradation mainly includes ecological remediation of soil erosion, desertification and ecological degradation caused by soil erosion and desertification. Through manual intervention to recover surface vegetation, increase biodiversity, protect production capacity of soil, improve watershed ecosystems, increase stability and anti-interference ability of ecosystem. Actual measures in ecological remediation practice are: One is biological measures with changing land use patterns. According to the specific situation, we increase biological factors by returning land for farming to forestry, retuning polder land to lake, returning cultivated land to grassland, closing hillsides to ban grazing, planting trees and grass and so on. Another one is engineering measures: improving the ecological environment factors by changing microtopography, leveling land, changing slope to terrace, building dams and so on. The remediation of ecological degradation has achieved remarkable effects in Inner Mongolia Area, the Loess Plateau and the vast mountainous areas of China. It not only kept down the ecological degradation of these areas and improved watershed ecological environment, but also optimized the local economic structure and improved the local people's living standards to a certain extent.

Practice of ecological remediation to environmental pollution. It is mainly based on the theory of material circulation, using biological factors of ecosystems to quickly transform harmful substances into harmless substances, and controlling the ecological structure to make its healthy development. Pollutants are mainly heavy metals, radioactive substances, toxic substances, organic substances and so on. Polycyclic aromatic hydrocarbons in organic compounds have carcinogenic, teratogenic and mutagenic effects on organisms, and pose threat to humans and other organisms. Heavy metal ions, pesticides and herbicides pose great threat to the survival of most animals and humans through the food chain accumulation and amplification effect.

Practice of ecological remediation to soil pollution. The traditional remediation method is high temperature combustion, cleaning, heating volatilization and so on. These methods have the disadvantages of high cost, destruction of soil structure and fertility. However ecological remediation 
has advantages of low investment, good effect, pure nature. It mainly uses biological factors in ecosystems (bioremediation) to repair soil: Utilizing microbial metabolic function to degrade pollutants. Utilizing the extraction, volatilization and stabilization of the plant to absorb and transform pollutants. Utilizing plant roots to provide a good living environment for microorganisms, and then absorb and transform pollutants. The specific methods are divided into in-situ remediation and ectopic remediation. Ectopic bioremediation includes bioreactor method, mud reflector method, soil accumulation, composting method and so on. Using microbial metabolism function to degrade soil pollutants, during in-situ bioremediation, firstly utilizing indigenous microorganisms, adding nutrients and electronic receptors to increase the number of microorganisms and activate microbial catabolic ability, and then rapidly degrade pollutants. As for pollutants that are difficult to degrade for indigenous microorganisms, adding specific microorganisms (group) to repair; furthermore the phyto-remediation which is emerged recent years and gradually becomes a research hotspot in bioremediation. Plant roots not only can secrete nutrients for microorganisms, activate microorganisms to degrade pollutants, but also can absorb and transform pollutants especially heavy metals and radioactive substances. According to the domestic and foreign research findings, there are more than 80,000 kinds of plants have repair function to soil pollution, of which more than 700 species used to repair heavy metal pollution. Soil ecological remediation has made great achievements.

Practice of ecological remediation to water pollution. The performances of hazards to aquatic ecosystems caused by pollutants are poison to aquatic organisms, water body eutrophication and the degradation of water ecosystems structures and functions caused by them. The ecological remediation to water pollution asks for removing pollutants from water, controlling algae outbreaks. The traditional remediation method is physical-chemical remediation, such as passivating pollutants in water and depositing it in the sediment, directly poisoning algae and separating algae by machinery. This method has a significant effect in the short term, but the passivated pollutants will re-release under appropriate conditions and make secondary pollution with chemical substances that used to poison algae. At the same time, bioremediation is widely used. Bioremediation is divided into microbial remediation, phyto-remediation and animal regulation. Microbial remediation utilizes effective flora (photosynthetic bacteria, nitrification-denitrifying bacteria, lactic acid bacteria and so on) to absorb and degrade pollutants and then inhibit algae outbreaks through competitive mechanisms; Phyto-remediation achieves the purpose of absorbing pollutants and controlling algae by bulk absorption, releasing material that inhibit algae and providing survival conditions for microbes; Animal regulation uses food chain control theory to maintain a large number of zooplankton and herbivore fish to eat algae, and then achieve the purpose of controlling algae outbreaks and transferring pollutants that absorbed by algae. Because the zooplankton and the algae are difficult to control, some algae are not edible, and the absorption of contaminated elements by plants and microorganisms is unitary, so a single bioremediation don't achieve desired effect recently. For this reason, we should use the principles of ecosystems to maintain the diversity of aquatic organisms, restore and rebuild healthy water ecosystems. While controlling algae outbreaks, the theory of using aquatic organisms to absorb, degrade and transform pollutants came into being and be used to water pollution remediation.

\section{THE DIFFICULTIES OF ECOLOGICAL REMEDIATION}

Human beings have a strong desire for remediation of ecological degradation and environmental pollution, hundredfold confidence and high enthusiasm. And they actively devote into the actual remediation work, but in the remediation process there are many difficulties that hinder the process.

\section{A. The Study Difficulties in the Theory and Technology of Ecological Remediation}

- The complex ecosystem health mechanism constituted by nature, society and economy has not clear yet. The harmonious relationship between human and nature is the theoretical basis and decision basis of ecological restoration. The flaws of the study on the natural, social and economic complex ecosystem health mechanism lead human activities to lack code of conduct in the coordinating process of social and economic development and natural ecology.

- We lack scientific evaluation standard of ecosystem health. It is generally believed that the ecosystem health is able to maximize the provision of ecological services for human, and evolves toward to the trend that propitious to the survival and development of human. There is no scientific and accurate evaluation system now, so we lack scientific basis about the degree of ecological restoration.

- The lack of research findings for interaction among the various factors of natural ecosystem and the evolving mechanisms of health ecosystem lead ecological remediation into lack the basis of target determination and technical application.

- The Natural ecosystems differences in tolerance thresholds of external disturbance perplex the implementation of remediation activities. Human activities are bound to interfere with the natural ecosystem, however different ecosystems and different evolution stages of ecosystems have different tolerance thresholds of human interference. The limits that human activities should be controlled don't have clear standard now.

- The lack of ready-made remediation technology and implementation plans increases the difficulty of technical research. Ecological remediation technology is essentially organic combination of a variety of biotechnology, engineering and other technologies. There is no ready-made general set of technology. Based on different ecosystems and their different 
degree of degradation, we should take appropriate technical combinations and implementation procedures.

\section{B. The Difficulties in Actualizing of Ecological}

\section{Remediation}

1) The coordination of current interests and long-term interests: The areas losing soil and water often have relatively backward economy. The implementation of ecological remediation will affect the local economy's current interests. In the process of remediation, we should solve three major issues of food, feed and fuel; we should take appropriate compensation and financial support, and increase support efforts; the policy should be played a role, linking mountain and closed grassland to the local economy, clearing property rights and so on. We should ensure that the local current interests can't be lost, and mobilize the enthusiasm of local people.

2) The coordination of different administrative regions and different interest groups within the basin: Ecological remediation is generally based on basin, and the implementation of remediation is characterized by comprehensiveness and synchronicity. There are some difficulties in the coordination of different administrative regions and different interest groups within the basin. Government should take administrative means, legal means and economic means to solve them.

\section{REFERENCE}

[1] Wang Zhi-guo. Approach to Concepts and Issues on Ecological Renovation [J]. Soil and water conservation in China, 2003, No.10: p4,p5,p39.

[2] Wang Wen-jun, Huang Dao-ming. Research Progress of River Restoration Research at Home and Abroad [J]. Journal of Hydroecology, 2012, Vol. 33 No. 4:p142-p145.

[3] Cui Shuang, Zhou Qi-xing. The researching progress and prospect of ecological remediation [J]. Pratacultural science, 2008, Vol.25.No.1:p87-p91.

[4] Liu Guo-bin, Yang Qin-ke, Chen Yun-ming. Some Scientific Issues of Ecological Restoration of Soil and Water Conservation[J]. Journal of Soil and Water Conservation, 2005, Vol.19 No.6:p126-p130.

[5] Deng Xiaofang. China Typical Mining Area Ecological Restoration Research Review [J]. Forestry economics, 2015, No.7:p14-p19.

[6] Chen Hongquan, Zhang Huabing. Ecological Restoration in Yangcheng Coastal Wetlands [J]. Transactions of Oceanology and Limnology, 2016, No.4:p43-p49. 